\title{
In Vitro Induction of Neural Differentiation of Embryonic Stem (ES) Cells Closely Mimics Molecular Mechanisms of Embryonic Brain Development
}

\author{
MICHELE CAZILLIS, SOWMYALAKSHMI RASIKA, SHYAMALA MANI, PIERRE GRESSENS, AND VINCENT LELIÉVRE
}

Inserm U676 [M.C., S.R., P.G., V.L.], U676, Paris, F-75019 France; Université Paris 7 [M.C, S.R., P.G., V.L.]; Faculté de Médecine

Denis Diderot, 75251 Paris, France; National Brain Research Centre [S.M.], Haryana, 122050, India; Service de Neurologie Pédiatrique

[P.G.], AP HP Hôpital Robert Debré, F-75019 Paris, France

\begin{abstract}
The capacity of pluripotent embryonic stem cells (ES cells) to proliferate and differentiate makes them promising tools in the field of cell therapy. In spite of the controversy surrounding the numerous ethical questions raised by this technology, it has been shown to have therapeutic potential for heart, lung, liver, bone and connective tissue regeneration. In addition, a very attractive aspect of this technology is its potential for the treatment of cerebral pathology. A number of studies using ES cell transplants report the differentiation of ES cells in the brain or spinal cord of rodents, and the improvement of locomotor and/or cognitive deficits caused by brain injury. This review offers a synthesis of recent advances in the field of both human and rodent stem cell manipulation to select populations of neurons, astrocytes and oligodendrocytes. In parallel, this review emphasizes the striking similarities that exist between genetically programmed embryonic development of the nervous system and the differentiation of ES cells in vitro. (Pediatr Res 59: 48R-53R, 2006)
\end{abstract}

$\mathrm{E}^{\mathrm{m}}$ mbryonic stem (ES) cells are isolated directly in culture from the inner cell mass (ICM) of pre-implanted embryos (blastocyst) $(1,2)$. They are self-renewing, pluripotent and capable of contributing to all the tissues of the embryo in vivo, and into the majority of cell types in vitro, with the exception of extra-embryonic tissue types, at least in the case of mouse ES cells (3). Interestingly, this differentiation process closely follows a genetic program similar to that turned on during embryonic development. Two principal methods are used for the differentiation of ES cells into neural cells. The first involves the formation of embryoid bodies, within which cells differentiate into the three germ layers and provide morphogenetic signals that are present in the embryo (4). The second method consists of culturing ES cells in various media conditions to direct neural differentiation and thereby to generate quasi-homogenous populations of neurons or glia.

\section{SELF-RENEWAL OF ES CELLS}

ES cells, which represent the very first stem cells of an embryo, are capable of self-renewal, i.e. they can theoretically

Received November 28, 2005; accepted December 8, 2005.

Correspondence: Pierre Gressens, M.D., Ph.D., Inserm U676, Hôpital Robert Debré, 48 Blvd Sérurier, 75019 Paris, France; e-mail:gressens@ rdebre.inserm.fr.

DOI: $10.1203 / 01 . p d r .0000203566 .01600 .8 \mathrm{c}$ undergo an infinite number of cell divisions without loss of potential. This process requires the activation of the STAT pathway by either IL-6 or LIF for promoting cell cycle progression and for the maintenance of the undifferentiated state (Fig. 1) (5,6). In vitro, the activation of STAT3 by LIF is sufficient for the self-renewal of mouse ES cells. Conversely, in the absence of STAT3 activation by LIF, mouse ES cells differentiate spontaneously $(5,7,8)$. However, LIF exhibits no obvious effects on human ES cell proliferation (9), suggesting that the role of Stat3 signaling in the self-renewal mechanism may differ between mouse and human ES cells. BMP signaling, involving the interaction of BMP (bone morphogenic proteins) with BMPR1 receptors and the subsequent activation of Smad effectors, also plays a critical role in ES cell selfrenewal. BMPR1 is highly expressed in mouse ES cells but down-regulated when cells differentiate. However BMP action is directly dependent on the presence of LIF in mouse ES cells. In its absence, BMP acts as a strong inducer of mesodermal differentiation while also inhibiting neuronal specification. These interactions between BMP and LIF pathways may occur downstream at the level of $\mathrm{CBP} / \mathrm{p} 300$ proteins to regulate gene expression (10).

In addition, two homeodomain transcription factors, NANOG and OCT4, that are highly expressed in the ICM and epiblastic cells of pre-implanted embryos also seem to exert strict control over the self-renewal versus the initiation of the differentiation process of stem cells (11-13). Permanent inactivation of the oct 4 gene prevents the establishment of pluripotent cell populations, and leads to developmental arrest (13), whereas stable transfection of OCT4 maintains selfrenewal and pluripotency of human ES cells (14). However, in culture conditions that induce neurogenesis, the loss of expression of oct 4 in ES cells encourages the formation of the endoderm, whereas its overexpression allows neuronal differentiation even in the absence of appropriate culture conditions (15). Similarly, the constitutive expression of NANOG in ES cells sustains cell potentials, while Nanog deprivation initiates differentiation into endodermal cells (16). Recent results indi- 


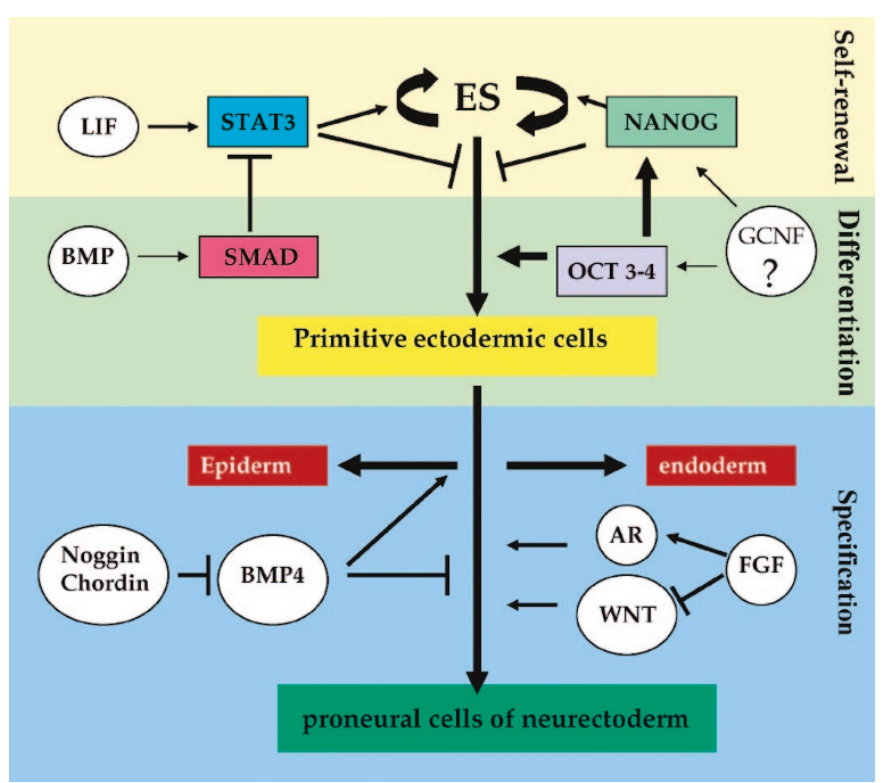

Figure 1. Pluripotentiality of ES cells and the induction of ES cell differentiation into cells of the neurectoderm: The proliferation of ES cells is carried out by LIF. LIF acts through the receptor subunit gp130 by activating STAT3. BMP activates SMAD, whose signaling pathway inactivates STAT3. NANOG is involved by activating the proliferation of ES cells and by inhibiting differentiation. In the absence of LIF, STAT3 is inactivated and the cells differentiate into endoderm. OCT4 induces the differentiation of ES cells into endodermal cells and inhibits the differentiation of the trophectoderm. The novel orphan nuclear receptor GCNF seems to directly activate both Nanog and Oct4 expression. Cells derived from ES cells differentiate into neurectodermal (proneural) cells. Inhibition by BMP4 induces neural specification. Factors permitting the inhibition of BMP4 lead to neural induction by default. Noggin and Chordin block the activity of BMP4. RA and the WNT pathway activate neurectodermal differentiation. The FGF pathway inhibits signaling by WNT and activates signaling by RA.

cate that OCT4 and NANOG act in concert on the proliferation and differentiation of ES cells, by means of molecular mechanisms that are most likely different but whose pathways cross talk (17).

\section{DIFFERENTIATION OF ES CELLS INTO PRECURSOR CELLS OF THE NEURECTODERM (SPECIFICATION)}

Neurectoderm is specified on the dorsal side of the embryonic ectoderm in part due to the inhibition of signaling pathways induced by proteins of the TGFb-family, such as BMP and nodal, by molecules secreted by the dorsal lip of the blastopore, also known as the organizer (18). Inhibition of BMP signaling along with the level of WNT and FGF signaling allows the neurectoderm to establish a rostro-caudal identity. As demonstrated over the last six decades in Xenopus, BMP4 inhibition by the factors Noggin, Follistatin and Chordin secreted from the organizer, is sufficient to induce neuralization, leading to the concept of the "default model." For instance, neural fate specification can be induced directly from mouse ES cells cultured at low density in the absence of any inducing supplements, suggesting that a default mechanism may prevail in the mouse to direct ES toward a neural stem cell stage (19). In contrast, expression patterns of BMP and their antagonists do not fit the default model in chick but also

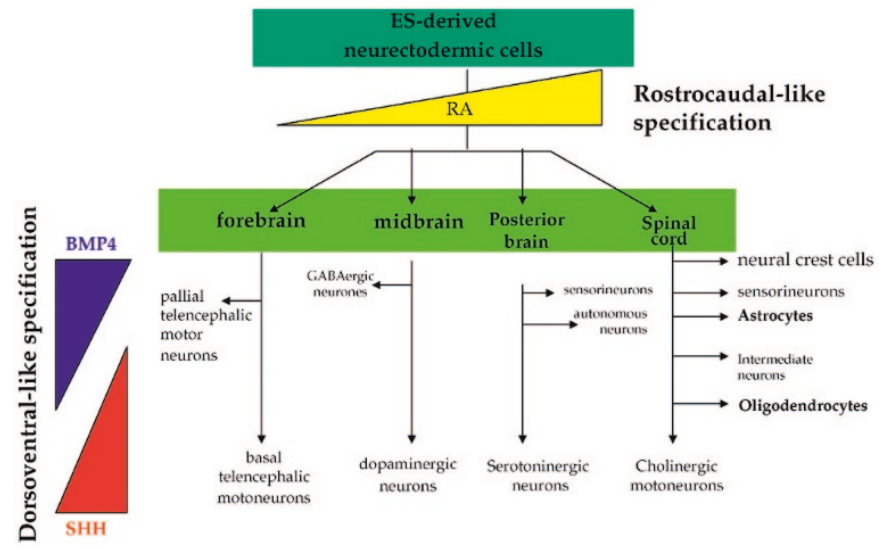

Figure 2. Differentiation of proneural cells deriving from ES cells into different types of neural cells: This schematic diagram illustrates the similarities between the spatiotemporal differentiation of ES cells into neurons and that occurring during embryonic development in vivo. In parallel with the RA-dependent rostrocaudal-like identification of the neural stem cells, the double antagonistic gradient of BMP and SHH plays a key role in dorsoventral patterning. The opposing effects of SHH and BMP4 on proneural cells generate precursor cells expressing selective markers that in vivo specified progenitor cells localized at the level of the roof, the midline or the floor plate of the differentiating neural tube. The different types of neurons generated from either mouse or human ES cells are localized along the concentration gradient that allows them to acquire their identity.

in mouse embryos, supporting the idea that other factors and signaling pathways, including FGFs and WNT may also be required for neural induction (for review, 18). Subsequently BMPs are also involved in the establishment of dorso-ventral identity of the neural tube (see section III).

Due to the absence of a three-dimensional structure, ES cells in culture depend upon the addition of factors for efficient neural induction. Experiments show that the neural induction pathway in ES cells is similar to that identified during embryonic development. Undifferentiated human ES cells show high expression levels of nodal and lefty (its own antagonist) and also of SMAD proteins, the downstream effectors of BMP and Nodal signaling pathways (20). High levels of active SMAD2/3 are correlated with maintenance of human ES cells in a pluripotent state (21). When differentiation of ES cells is initiated, a decrease in SMAD 2/3 activation and the expression of nodal and lefty is observed (20). In addition, the WNT signaling pathway interacts with the BMP signaling pathway to regulate the levels of SMAD 2/3 (20). Interestingly in this context, there is a difference between mouse ES cells and human ES cells. While mouse ES cells maintain pluripotency in the presence of WNT signaling as assessed by the expression of Oct $3 / 4$, this effect is not correlated with levels of active SMAD2/3. In contrast, in human ES cells, maintenance of Oct3/4 expression is correlated with active SMAD 2/3 (21).

The results discussed in the preceding paragraph thus suggest that the balance between the induction of cell fates and the maintenance of pluripotency in human ES cells may be due to a conserved reciprocal interaction involving similar signaling pathways. The FGF signaling pathway also intersects with the BMP signaling pathway, and for human ES cells, the addition of FGF-2 helps to maintain the pluripotency of ES cells $(22,23)$. However, it is the balance between BMP, 
WNT and FGF signaling pathways that determines whether addition of exogenous FGF2 leads to maintenance of human ES cells in an undifferentiated state or whether FGF2 helps in expanding a population of FGF-dependent neural precursor cells.

The organizer secretes antagonists of BMP signaling such as Noggin, Chordin and Follistatin, whose loss reduces specification of ectoderm to neurectoderm. The contextual role of these signaling pathways is highlighted by the fact that ES cells simultaneously produce BMP4 as well as the inhibitors of its own signaling pathway, Noggin and Chordin, at very low concentrations. Therefore either the absence of exogenous BMP4 (24) or overexpression of Noggin or Chordin leads to an increase in the number of differentiated colonies generated from ES cells. A selective inhibition of the WNT pathway in ES cells prevents neural differentiation and enhances the regulated expression of the specific inhibitors of neural differentiation (25-27). In parallel, FGF4, by inducing the expression of neuronal markers, appears sufficient but not absolutely necessary for the differentiation of ES cells in culture. While its presence assures the proliferation of differentiating cells, its absence induces neural differentiation $(6,28,29)$. Finally, endogenous retinoic acid (RA) is also required for the establishment of neural specification in embryos, as well as the induction of neural differentiation of embryoid bodies in culture (30).

To summarize, these results indicate that ES cells undergo specification to generate neural progenitors cells according to mechanisms similar to those that occur during embryonic development in vivo. In particular, inhibitors of BMP4 induce neuralization in concert with supporting factors such as WNT, FGF and RA. The action of BMP is context-dependent as suppression of BMP signaling in floating aggregates of human ES cells leads to induction of neural tissue (31) while in a different context the interaction of these signals gives rise to differentiation of cardiac muscle (32). The signaling pathways responsible for neural specification are also involved in the acquisition of dorso-ventral identity at a later stage (see next section).

\section{PRONEURAL CELLS DERIVED FROM ES CELLS ACQUIRE BOTH ROSTROCAUDAL AND DORSOVENTRAL IDENTITIES OF STEM CELLS IN THE EMBRYO}

Retinoic acid has been identified as a caudalizing factor that, along with FGF and WNT, is important for the neuronal fate of ES cells during the specification of the rostrocaudal axis of the embryonic brain $(33,34)$. Further, in ES cells, the addition of RA along with aggregation of cells leads to neural differentiation in a dose-dependent manner (35). When mouse ES cells are specified to become neural progenitor cells, the phenotype obtained is consistent with RA acting as a caudalizing molecule. Thus the absence of RA results in the appearance of neuronal progenitor cells which express the anterior forebrain markers emx1/2 and nkx2.1, as well as Bf1, a telecenphalic marker (36), while low doses of RA result in the generation of cells that express markers for midbrain neurons
(37). High RA concentrations result in a caudal phenotype with expression of posterior markers such as Hoxc5/6 instead of anterior markers (i.e. Otx2 or En1), and in concert with sonic hedgehog (SHH) signaling, lead to the differentiation of motor neurons (38). At the level of the anterior neural plate, Wnt signaling exclusion is required for the acquisition of telencephalic characteristics, whereas its activation is required for caudal specification (39). The inhibition of the FGF signaling pathway suppresses the expression of the RA receptor, and the overexpression of RARa, the RA receptor, restores the effects of FGF, demonstrating the interaction between the RA and FGF pathways in specifying the rostrocaudal neural axis, and suggesting that RARa is a direct target for the FGF signaling pathway (40).

\section{BMP4 DIFFERENTIATES ES-DERIVED PRONEURAL CELLS INTO NEURONAL PRECURSORS AND NEURAL CREST CELLS (DORSALIZATION)}

In the embryo, BMP4 is secreted by the roof plate of the neural tube and forms a dorsal gradient. Depending upon the position of neural precursors along the rostrocaudal axis, the local concentration of BMP-4 specifies the neural phenotype outcomes. Thus in culture conditions (low RA concentrations) that anteriorize the neural precursors, the absence of SHH as a ventralizing factor induces the generation of pallial telencephalic $\left(\mathrm{Pax}^{+}\right)$neurons (36). Furthermore, in serum-free culture conditions compatible with telecenphalic specification (no RA addition and repression of WNT and nodal), Pax6- ${ }^{+}$ cells can be further differentiated into neural retinal precursors (41). Neural progenitor cells derived from ES cells grown in defined media when exposed to BMP4 will also progressively acquire the characteristics of dorsal neurons and neural crest cells (35). Thus the presence of BMP4 increases the number of cells expressing markers of the neural crest (including snail, slug and Msx1) while reducing the expression of ventral markers (i.e. nkx2.2 and HNF3 $\beta$ ). In addition, depending upon the dose used, BMP4 induces the differentiation of neural crest precursors into sensory neurons (Brn3a/Peri), or autonomic neurons (TH/Peri). The above results suggest that the role of BMP4 as a dorsalizing factor in the embryo is also observed in ES cells that have been specified to undergo a neural fate. (Fig. 2).

SHH induces ventral differentiation in proneural cells derived from ES cells to generate motoneurons. In the mouse embryo, SHH is initially produced by the notochord, and then by the floor plate cells of the neural tube. This peptide diffuses along a concentration gradient in the ventral portion of the neural tube to allow the local differentiation of ventral precursors (18); the loss of SHH or the interruption of its signaling pathway results in the dorsalization of the embryo by the expansion of regions under the control of BMP4, leading to a pathology known in humans as holoprosencephaly (42), whereas constitutive expression of SHH triggers a lethal overall outgrowth of embryonic neural tube and suppresses the differentiation of dorsal regions (43). Gene mutations leading to partial gain of hedgehog functions result in the formation of 
multiple cancers including medulloblastomas and skin nevoid basal cell carcinomas, also known as Gorlin's syndrome (44). Several studies have shown that embryoid bodies derived from murine ES cells express two of the three members of the hedgehog family, Indian hedgehog (ihh) as well as Sonic (shh; unpublished data), at the level of the outer visceral endoderm, and direct effectors of its signaling cascade (i.e. patched and gli1) in the inner endoderm (45). A recent study has shown that along with its role in dorsoventral patterning, $\mathrm{SHH}$ is also required for the specification of neurectoderm as well as the responsiveness of ES cells to other neural inducers such as RA (46). Thus, in the presence of increasing concentrations of $\mathrm{SHH}$, differentiating mouse ES cells expressing markers for the neural crest and for dorsal neurons (Pax7 and Math1) are reduced or disappear, while cells expressing ventral markers (nkx2.2 and HNF3 $\beta$ ) are augmented (35) (Fig. 2). Mouse embryoid bodies cultured in serum-free medium supplemented with SHH and FGF-8, develop high yields of TuJ1positive neuroblasts that express either dopaminergic or serotoninergic markers (46) and may represent in vitro models of ventral midbrain-hindbrain neurons.

In mouse ES cells that have been have been cultured on stromal cells to induce neural differentiation, the presence of higher concentrations of $\mathrm{SHH}$ results in an increase in the differentiation of neuronal cells expressing ventral markers (nkx2.2 and HNF3 $\beta$ ) along with a decrease in the markers for neural crest and for dorsal neurons (Pax7 and Math1). At a later time during differentiation other markers that identify more specialized populations of cells, such as basal telencephalic motoneurons or brachiomotor and visceral neurons, appear (35,36) (Fig. 2). Similar motor neuron phenotypes were also obtained with human ES cells that were "caudalized" by exposure to RA and "ventralized" in the presence of SHH (46). Finally, SHH signaling, along with FGF8 signaling, leads to the specification and differentiation of dopaminergic neurons. Differentiation of neural progenitors in both mouse and human ES cells into dopaminergic neurons is correlated with the expression of genes such as Nurr1, Lmx1b and Ptx 3 that are involved in the patterning and differentiation of dopaminergic neurons during embryonic development (47). Overexpression of the nuclear receptor Nurr1 has been shown to potentiate the effects of SHH and FGF8 on neuronal differentiation of mouse ES cells (48). Mouse ES cell lines expressing Nurr1 develop functional characteristics of dopaminergic (DA) neurons after transplantation into the brain of rat models of Parkinson's disease (49). Similar dopaminergic differentiation has been achieved using human ES cells (50); unfortunately, however, these DA-derived human ES cells do not seem to survive and /or retain their dopaminergic phenotype when grafted into rat brain (51).

\section{DIFFERENTIATION OF GLIA (ASTROCYTES AND OLIGODENDROCYTES}

In contrast to the strong interest in neuron generation, in vitro differentiation of ES cells into glia has received very limited attention. During development, gliogenesis occurs at a later time than neurogenesis in the ventral and dorsal zones of the neural tube. This timing is partially controlled by $\mathrm{SHH}$ and involves the expression of the transcription factors olig2 and nkx2.2 (52). Olig2 is alternatively expressed in ventral oligodendrocytic (OL) progenitors or suppressed in neurons and astrocytes. OL fate is reduced or delayed in nkx2.2 or olig2-/mice, whereas progenitor cells expressing olig2 successfully myelinize axons in culture and in vivo in the injured spinal cord (29,53). ES cells can differentially generate glial cell populations including astrocytes, oligodendrocytes and microglia, according to a sequential process whose dynamics resemble that of the mechanisms involved in utero $(54,55)$. Thus, olig2-overexpressing ES cells selectively generate oligodendrocytes and motor neurons (56) and FGF2 and SHH act synergistically to induce OL progenitor formation from embryoid bodies (46) (Fig. 2). The generation of highly-purified olidendrocyte progenitors from mouse ES cells has been recently reported using culture conditions that combined FGF-2, PDGF and T3 supplements (57).

Neural differentiation of mouse and human ES cells always give rise to a fraction of "contaminating" GFAP-positive cells among the desired populations of neuron or oligodendrocyte progenitors, suggesting that these ES-derived neural stem cell progenitors share the potential to generate both neuronal and glial lineages. However, the differentiation of astrocytes also appears to be under the influence of BMP4 at the level of the dorsal neural tube, suggesting that at least a fraction of astrocytic populations may have an origin distinct from that of ventral OL progenitors. Despite the lack of interest in cell therapy involving ES-derived astrocytes, replenishment may soon become useful as a therapeutic approach in the dramatic case of Alexander's disease, a fatal neurologic illness characterized by white-matter degeneration and the formation of astrocytic cytoplasmic inclusions called Rosenthal fibers, due to mutations in the gene encoding GFAP proteins (58).

Finally, it is also worth noting here that neural stem cells found in both mouse and human adult brains are characterized by the expression of GFAP, suggesting that they may share common properties with astrocytes $(59,60)$.

\section{CONCLUSION}

The results discussed above, taken as a whole, demonstrate that the neural differentiation of ES cells in culture progresses according to a genetic program similar to that observed in the embryo. In the absence of a three-dimensional structure, ES cells are a priori capable of giving rise not only to all populations of neurons (motor, sensory and associative) produced in vivo, but also to cells in the oligo-astroglial lineage. The culture of ES cells in the presence of extracellular morphogenetic signals originally identified in embryos as inducers of the positional patterning of specialized cell populations can generate similar cell subtypes, according to a program comparable in certain respects to that occurring in the embryo. In this context, the use of naïve or pre-differentiated ES cells appears to be a definite advance in the treatment of animal models of human neurodegenerative disorders. Using this approach a number of recent studies involving the transplantation of stem cells into the brain of mice exhibiting neuronal 
pathologies similar to human disorders have met with success (49). However, in the case of leukoencephalopathies, the goal is to generate oligodendrocytes or Schwann cells from ES cells, to myelinate or remyelinate CNS axons on transplantation. While mouse ES cells exhibit this capacity, oligodendrocyte differentiation from human ES cells remains to be optimized before it can be potentially tested in human pathologies (such as Pelizaeus-Merzbacher disease) (61). One technical limitation that is being rapidly overcome is that most of the human ES cell lines currently used in in vitro studies are contaminated with bovine or murine determinants that are the result of culture conditions, precluding their use in cell therapy. Therefore, new culture protocols based on the use of human feeder cells or artificial three dimensional substrates have recently shown potential to pave the way for human ES cells in cellular therapy (62).

\section{REFERENCES}

1. Evans MJ, Kaufman MH 1981 Establishment in culture of pluripotential cells from mouse embryos. Nature 292:154-156

2. Martin GR 1981 Isolation of a pluripotent cell line from early mouse embryos cultured in medium conditioned by teratocarcinoma stem cells. Proc Natl Acad Sci USA 78:7634-7638

3. Itskovitz-Eldor J, Schuldiner M, Karsenti D, Eden A, Yanuka O, Amit M, Soreq H, Benvenisty N 2000 Differentiation of human embryonic stem cells into embryoid bodies compromising the three embryonic germ layers. Mol Med 6:88-95

4. Takeda K, Noguchi K, Shi W, Tanaka T, Matsumoto M, Yoshida N, Kishimoto T, Akira S 1997 Targeted disruption of the mouse Stat3 gene leads to early embryonic lethality. Proc Natl Acad Sci USA 94:3801-3804

5. Li M, Sendtner M, Smith A 1995 Essential function of LIF receptor in motor neurons. Nature 378:724-727

6. O'Shea KS 2004 Self-renewal vs. differentiation of mouse embryonic stem cells. Biol Reprod 71:1735-1765

7. Nichols J 2001 Introducing embryonic stem cells Curr Biol 11:R503-R505

8. Humphrey RK, Beattie GM, Lopez AD, Bucay N, King CC, Firpo MT, Rose-John S, Hayek A 2004 Maintenance of pluripotency in human embryonic stem cells is STAT3 independent. Stem Cells 2522-2530

9. Nakashima H, Otsuka T, Ohba Y, Akahoshi M, Nagano S, Ogami E, Arinobu Y, Miyake K, Inoue Y, Niiro H, Kaji Y, Niho Y 1999 Two polymorphisms within interleukin-3 (hIL3) gene detected by mismatch PCR/RFLP. Genes Immun 1:156168

10. Rao M 2004 Conserved and divergent paths that regulate self-renewal in mouse and human embryonic stem cells. Dev Biol 275:269-286

11. Niwa H 2001 Molecular mechanism to maintain stem cell renewal of ES cells. Cell Struct Funct 26:137-148

12. Nichols J, Smith A, Buehr M 1998 Rat and mouse epiblasts differ in their capacity to generate extraembryonic endoderm. Reprod Fertil Dev 10:517-525

13. Nichols J, Zevnik B, Anastassiadis K, Niwa H, Klewe-Nebenius D, Chambers I, Schöler H, Smith A 1998 Formation of pluripotent stem cells in the mammalian embryo depends on the POU transcription factor Oct4. Cell 95:379-391

14. Gerrard L, Zhao D, Clark AJ, Cui W 2005 Stably transfected human embryonic stem cell clones express OCT4-specific green fluorescent protein and maintain selfrenewal and pluripotency. Stem Cells 23:124-133

15. Shimozaki K, Nakashima K, Niwa H, Taga T 2003 Involvement of Oct $3 / 4$ in the enhancement of neuronal differentiation of ES cells in neurogenesis-inducing cultures. Development 130:2505-2512

16. Mitsui K, Tokuzawa Y, Itoh H, Segawa K, Murakami M, Takahashi K, Maruyama M, Maeda M, Yamanaka S 2003 The homeoprotein Nanog is required for maintenance of pluripotency in mouse epiblast and ES cells. Cell 113:631-642

17. Kuroda T, Tada M, Kubota H, Kimura H, Hatano SY, Suemori H, Nakatsuji N, Tada T 2005 Octamer and Sox elements are required for transcriptional cis regulation of Nanog gene expression. Mol Cell Biol 25:2475-2485

18. Stern CD 2005 Neural induction: old problem, new findings, yet more questions. Development 132:2007-2021

19. Tropepe V, Hitoshi S, Sirard C, Mak TW, Rossant J, van der Kooy D 2001 Direct neural fate specification from embryonic stem cells: a primitive mammalian neural stem cell stage acquired through a default mechanism Neuron 30:65-78

20. Besser D 2004 Expression of nodal, lefty-a, and lefty-B in undifferentiated human embryonic stem cells requires activation of Smad2/3. J Biol Chem 279:45076-45084

21. James D, Levine AJ, Besser D, Hemmati-Brivanlou A 2005 TGFbeta/activin/nodal signaling is necessary for the maintenance of pluripotency in human embryonic stem cells. Development 132:1273-1282

22. Vallier L, Alexander M, Pedersen RA 2005 Activin/Nodal and FGF pathways cooperate to maintain pluripotency of human embryonic stem cells. J Cell Sci 118:4495-4509
23. Xu RH, Peck RM, Li DS, Feng X, Ludwig T, Thomson JA 2005 Basic FGF and suppression of BMP signaling sustain undifferentiated proliferation of human. ES Cells 2:185-190

24. Wilson SI, Edlund T 2001 Neural induction: toward a unifying mechanism. Nat Neurosci 4:1161-1168

25. Varga AC, Wrana JL 2005 The disparate role of BMP in stem cell biology. Oncogene 24:5713-5721

26. Aubert J, Dunstan H, Chambers I, Smith A 2002 Functional gene screening in embryonic stem cells implicates Wnt antagonism in neural differentiation. Nat Biotechnol 20:1240-1245

27. Haegele L, Ingold B, Naumann H, Tabatabai G, Ledermann B, Brandner S 2003 Wn signalling inhibits neural differentiation of embryonic stem cells by controlling bone morphogenetic protein expression. Mol Cell Neurosci. 24:696-708

28. Kielman MF, Rindapaa M, Gaspar C, van Poppel N, Breukel C, van Leeuwen S, Taketo MM, Roberts S, Smits R, Fodde R 2002 Apc modulates embryonic stem-cell differentiation by controlling the dosage of beta-catenin signaling. Nat Genet 32:594-605

29. Brustle O, Jones KN, Learish RD, Karram K, Choudhary K, Wiestler OD, Duncan ID, McKay RD 1999 Embryonic stem cell-derived glial precursors: a source of myelinating transplants. Science 285:754-756

30. Munoz-Sanjuan I, Brivanlou AH 2002 Neural induction, the default model and embryonic stem cells. Nat Rev Neurosci 3:271-280

31. Itsykson P, Ilouz N, Turetsky T, Goldstein RS, Pera MF, Fishbein I, Segal M, Reubinoff BE 2005 Derivation of neural precursors from human embryonic stem cells in the presence of noggin Mol Cell Neurosci 30:24-36

32. Yuasa S, Itabashi Y, Koshimizu U, Tanaka T, Sugimura K, Kinoshita M, Hattori F, Fukami S, Shimazaki T, Ogawa S, Okano H, Fukuda K 2005 Transient inhibition of BMP signaling by Noggin induces cardiomyocyte differentiation of mouse embryonic stem cells. Nat Biotechnol 23:607-611

33. Czyz J, Wobus A 2001 Embryonic stem cell differentiation: the role of extracellular factors. Differentiation 68:167-174

34. Lang KJ, Rathjen J, Vassilieva S, Rathjen PD 2004 Differentiation of embryonic stem cells to a neural fate: a route to re-building the nervous system? J Neurosci Res 76:184-192

35. Mizuseki K, Sakamoto T, Watanabe K, Muguruma K, Ikeya M, Nishiyama A, Arakawa A, Suemori H, Nakatsuji N, Kawasaki H, Murakami F, Sasai Y 2003 Generation of neural crest-derived peripheral neurons and floor plate cells from mouse and primate embryonic stem cells. Proc Natl Acad Sci USA 100:5828-5833

36. Watanabe K, Kamiya D, Nishiyama A, Katayama T, Nozaki S, Kawasaki H, Watanabe Y, Mizuseki K, Sasai Y 2005 Directed differentiation of telencephalic precursors from embryonic stem cells. Nat Neurosci 8:288-296

37. Okada Y, Shimazaki T, Sobue G, Okano H 2004 Retinoic-acid-concentrationdependent acquisition of neural cell identity during in vitro differentiation of mouse embryonic stem cells. Dev Biol 275:124-142

38. Wichterle H, Lieberam I, Porter JA, Jessell TM 2002 Directed differentiation of embryonic stem cells into motor neurons. Cell 110:385-397

39. Gunhaga L, Marklund M, Sjodal M, Hsieh JC, Jesssell TM, Edlund T 2003 Specification of dorsal telencephalic character by sequential Wnt and FGF signaling. Nat Neurosci 6:701-707

40. Shiotsugu J, Katsuyama Y, Arima K, Baxter A, Koide T, Song J, Chandraratna RA, Blumberg B 2004 Multiple points of interaction between retinoic acid and FGF signaling during embryonic axis formation. Development 131:2653-2667

41. Ikeda H, Osakada F, Watanabe K, Mizuseki K, Haraguchi T, Miyoshi H, Kamiya D, Honda Y, Sasai N, Yoshimura N, Takahashi M, Sasai Y 2005 Generation of $\mathrm{Rx}+/$ Pax6 + neural retinal precursors from embryonic stem cells. Proc Natl Acad Sci USA 102:11331-11336

42. Roessler E, Belloni E, Gaudenz K, Jay P, Berta P, Scherer SW, Tsui LC, Muenke M 1996 Mutations in the human Sonic Hedgehog gene cause holoprosencephaly. Nat Genet 14:357-360

43. Ruiz i Altaba A, Stecca B, Sanchez P 2004 Hedgehog-Gli signaling in brain tumors: stem cells and paradevelopmental programs in cancer. Cancer Lett 204:145-157

44. Unden AB, Holmberg E, Lundh-Rozell B, Stahle-Backdahl M, Zaphiropoulos PG, Toftgard R, Vorechovsky I 1996 Mutations in the human homologue of Drosophila patched (PTCH) in basal cell carcinomas and the Gorlin syndrome: different in vivo mechanisms of PTCH inactivation. Cancer Res 56:4562-4565

45. Maye P, Becker S, Kasameyer E, Byrd N, Grabel L 2000 Indian hedgehog signaling in extraembryonic endoderm and ectoderm differentiation in ES embryoid bodies. Mech Dev 94:117-132

46. Maye P, Becker S, Siemen H, Thorne J, Byrd N, Carpentino J, Grabel L 2004 Hedgehog signaling is required for the differentiation of ES cells into neurectoderm. Dev Biol 265:276-290

47. Barberi T, Klivenyi P, Calingasan NY, Lee H, Kawamata H, Loonam K, Perrier AL, Bruses J, Rubio ME, Topf N, Tabar V, Harrison NL, Beal MF, Moore MA, Studer L 2003 Neural subtype specification of fertilization and nuclear transfer embryonic stem cells and application in parkinsonian mice. Nat Biotechnol 21:1200-1207

48. Chung S, Sonntag KC, Andersson T, Bjorklund LM, Park JJ, Kim DW, Kang UJ, Isacson O, Kim KS 2002 Genetic engineering of mouse embryonic stem cells by Nurr1 enhances differentiation and maturation into dopaminergic neurons. Eur J Neurosci 16:1829-1838

49. Kim JH, Auerbach JM, Rodriguez-Gomez JA, Velasco I, Gavin D, Lumelsky N, Lee SH, Nguyen J, Sanchez-Pernaute R, Bankiewicz K, McKay R 2002 Dopamine neurons derived from embryonic stem cells function in an animal model of Parkinson's disease. Nature 418:50-56

50. Zeng X, Cai J, Chen J, Luo Y, You ZB, Fotter E, Wang Y, Harvey B, Miura T, Backman C, Chen GJ, Rao MS, Freed WJ 2004 Dopaminergic differentiation of human embryonic stem cells. Stem Cells 22:925-940 
51. Park CH, Minn YK, Lee JY, Choi DH, Chang MY, Shim JW, Ko JY, Koh HC, Kang MJ, Kang JS, Rhie DJ, Lee YS, Son H, Moon SY, Kim KS, Lee SH 2005 In vitro and in vivo analyses of human embryonic stem cell-derived dopamine neurons. J Neurochem 92:1265-1276

52. Chandran S, Kato H, Gerreli D, Compston A, Svendsen CN, Allen ND 2003 FGF-dependent generation of oligodendrocytes by a hedgehog-independent pathway. Development 130:6599-6609

53. Liu S, Qu Y, Stewart TJ, Howard MJ, Chakrabortty S, Holekamp TF, McDonald JW 2000 Embryonic stem cells differentiate into oligodendrocytes and myelinate in culture and after spinal cord transplantation. Proc Natl Acad Sci USA 97:6126-6131

54. Angelov DN, Arnhold S, Andressen C, Grabsch H, Puschmann M, Hescheler J, Addicks K 1998 Temporospatial relationships between macroglia and microglia during in vitro differentiation of murine stem cells. Dev Neurosci 20:42-51

55. Billon N, Jolicoeur C, Ying QL, Smith A, Raff M 2002 Normal timing of oligodendrocyte development from genetically engineered, lineage-selectable mouse ES cells. J Cell Sci 115:3657-3665

56. Xian H, Gottlieb DI 2004 Dividing Olig2-expressing progenitor cells derived from ES cells. Glia 47:88-101
57. Glaser T, Perez-Bouza A, Klein K, Brustle O 2005 Generation of purified oligodendrocyte progenitors from embryonic stem cells FASEB J 19:112-114

58. Johnson AB, Brenner M 2003 Alexander's disease: clinical, pathologic, and genetic features. J Child Neurol 18:625-632

59. Doetsch F, Caille I, Lim DA, Garcia-Verdugo JM, Alvarez-Buylla A 1999 Subventricular zone astrocytes are neural stem cells in the adult mammalian brain. Cell 97:703-716

60. Quinones-Hinojosa A, Sanai N, Soriano-Navarro M, Gonzalez-Perez O, Mirzadeh Z, Gil- Perotin S, Romero-Rodriguez R, Berger MS, Garcia-Verdugo JM, AlvarezBuylla A 2005 Cellular composition and cytoarchitecture of the adult human subventricular zone: a niche of neural stem cells. J Comp Neurol 494:415-434

61. Duncan ID 2005 Oligodendrocytes and stem cell transplantation: their potential in the treatment of leukoencephalopathies. J Inherit Metab Dis 28:357-368

62. Draper JS, Moore HD, Ruban LN, Gokhale PJ, Andrews PW 2004 Culture and characterization of human embryonic stem cells. Stem Cells Dev 13:325-336

63. Gu P, LeMenuet D, Chung AC, Mancini M, Wheeler DA, Cooney AJ 2005 Orphan nuclear receptor GCNF is required for the repression of pluripotency genes during retinoic acid-induced embryonic stem cell differentiation. Mol Cell Biol 25:8507-8519 